\title{
Lourdes Gaitán, Yannis Pechtelidis, Catarina Tomás y Natália Fernandes (eds.). Children's Lives in Southern Europe. Contemporary Challenges and Risks. Reino Unido y Massachusetts: Edward Elgar Publishing, 2020, 247 páginas
}

\author{
Irene Lebrusán \\ TRANSOC, Instituto Complutense de Sociología para el Estudio de \\ las Transformaciones Sociales Contemporáneas, España \\ ilebrusan@hotmail.com
}

Los estudios de la infancia, a pesar de destacables avances en los últimos años, es un campo de investigación aún en desarrollo. Los análisis de esta etapa vital cometen, en ocasiones, el error de perder de vista la agencia de los propios actores (niños, niñas y adolescentes) o de reducir la realidad experimentada desde una compresión adultocéntrica del mundo. Es habitual que los análisis de la infancia se elaboren desde una posición en la que ellos reciben, pero no emiten, olvidando asi su papel como actores de su propia vida.

Esta visión se enmarca en la dificultad (señalada por los editores en el capítulo de cierre) previa de encontrar información adecuada a la realidad de esta etapa vital, como podemos comprobar en la búsqueda de estadísticas, por ejemplo, o cuando analizamos las políticas especialmente dirigidas a la infancia y la adolescencia, más allá de su papel como hijos e hijas. Por otra parte, algunos estudios corren el riesgo de plantear el análisis de la infancia como contraposición a la vida adulta, como una mera etapa previa, o bien comprenden la infancia como un constructo que anula otras variables de relevancia (como la clase social), negando así no solo las diferencias sino la complejidad del análisis de este grupo etario. Este es uno de los motivos por los que el libro editado por Gaitán, Pechtelidis, Tomás y Fernandes resulta, sin duda, necesario.

La justificación investigativa del libro es aún mayor, pues se centra en la situación de la infancia en los países del sur de Europa (muy poco explorada) prestando atención a sus diferencias, pero partiendo del marco común establecido por sistemas de bienestar similares y las múltiples semejanzas sociales, económicas y políticas. Como señala Manuel Jacinto Sarmento en la introducción, "perhaps this will be the major contribution of a southern sociology of childhood" (Sarmento, 2020, p. xvii).

Visibilizar a quienes viven su infancia en los países del Sur de la Unión Europea (Grecia, Italia, Portugal y España) resulta un tema especialmente relevante en un contexto claro de cambio social en el que aparecen nuevos riesgos y aumenta la desigualdad que, además, se ha agudizado en la infancia. El volumen se estructura en tres partes claramente diferenciadas, recogiendo en cada una de ellas algunos de los desafios principales surgidos con las recientes crisis (económica, pero también migratoria) y ante un marco político, económico y social de turbulencia. Los temas analizados no serán nuevos al lector, pero sí lo será el abordaje de los mismos.

La primera parte se centra en la caracterización de los niños en las sociedades envejecidas del sur de Europa como una minoría demográfica, pero también como un grupo 
social minoritario que construye, en su día a día, una reconceptualización en la forma de experimentar y vivir la infancia. Este apartado reflexiona sobre los cambios demográficos y su impacto el sistema de protección, pero también en cómo han cambiado la familia y las relaciones familiares, los cuidados, las pautas de convivencia y, más allá, en cómo todos estos factores impactan en la dimensión simbólica y comprensiva de la infancia.

La segunda parte realiza una reflexión muy necesaria sobre las consecuencias que ha tenido la crisis financiera en las sociedades del sur de Europa, haciendo hincapié en cómo ha afectado a la vida de los niños y niñas. Como señala una de las autoras: "It is hard for children to escape conditions of poverty" (Tagliaventi, 2020, p. 107). Se refieren así, situaciones de empobrecimiento no solo en términos económicos, sino de pérdida de oportunidades ante el aumento de la desigualdad. Especialmente interesante es el aporte sobre cómo el aumento de la pobreza no ha impactado por igual en todos los grupos socioeconómicos, sino que determinados grupos de niños, niñas y adolescentes (como las etnias minoritarias) han resultado especialmente afectados. Se reflexiona también sobre cómo las políticas de austeridad han afectado al deterioro de la calidad de vida de los niñas y niñas en términos generales.

Por último, la tercera parte se centra en la experiencia y situación de los niños migrantes, recordando el papel que los niños y niñas juegan en los contingentes migratorios, trayendo a la luz sus voces y deseos, pero también mostrando las contradicciones que existen en las sociedades receptoras y que se manifiestan en las políticas existentes (o en su ausencia). Este apartado es esencialmente relevante en la actualidad, cuando tan a menudo se superpone el rol de migrante al rol de niño y se olvida la especial situación de vulnerabilidad que experimentan cuando se conjugan ambos roles, especialmente en el caso de quienes se ven obligados a migrar solos. Especialmente interesante resulta el análisis de cómo las sociedades del sur se adaptan (si es que lo hacen) a la infancia migrante. Desde el punto de vista sociológico los estudios de caso nos permiten considerar, en primer lugar, los defectos estructurales y las limitaciones de las relaciones de poder contemporáneas en la subjetividad de los niños y el tratamiento político de temas sociales vitales como el bienestar y la prosperidad de los niños migrantes, la integración social y la educación. En segundo lugar, recoger las experiencias de los niños migrantes y refugiados y migrantes nos permite reconstruir sus narrativas sobre las dificiles circunstancias en las que viven sus necesidades y sus estrategias para lidiar con estas situaciones.

En total, el libro recoge doce estudios de caso en los países señalados, siempre teniendo en cuenta las especificidades de cada uno de ellos, pero que nos ayudan a comprender la situación de la infancia en un contexto de similitudes tanto culturales como desde el punto de vista del estado del bienestar, sus políticas de protección y sus limitaciones. La filosofia tras cada uno de los análisis es la de superar el mero análisis descriptivo para ahondar en el papel de los niños y niñas como actores protagonistas de su propia vida y de la infancia como fenómeno social que ha de ser estudiado teniendo en cuenta las variaciones inherentes a la sociedad en la que se desarrolla.

La estructura del libro lo hace fácil de leer, siguiendo una clara línea argumental en torno a los tres grandes temas señalados, que se eligen por ser comunes en cómo han afectado a los países del sur, pero a la vez indagando, a partir del estudio de caso, en cómo cada país del sur refiere diferencias constatables. Cada estudio de caso expone previamente las tendencias principales, entre las que se incluyen datos estadísticos (que permiten contextualizar los fenómenos también en la dimensión temporal) así como los debates teóricos y las políticas aplicadas en el país analizado. La diversidad de técnicas cualitativas y cuantitativas reflejadas (incluyendo el análisis de narrativa gráfica) es otro aspecto destacable, aunque siempre replicando la misma estructura y facilitando así su lectura. La importancia de la estructura no es menor en un momento en el que es 
habitual encontrar obras colectivas sin estructura común, perdiendo así la oportunidad de reconstruir y establecer los vínculos de análisis en diferentes contextos. No sucede así en este volumen.

El libro recupera el papel de los niños en diferentes procesos sociales y cómo niños y niñas están conformando un cambio en las sociedades europeas y en los que suele ignorarse no solo el papel de la infancia, sino la retroalimentación entre esta y el referido cambio social. Lo más interesante es precisamente tener en cuenta la perspectiva de la infancia en procesos que se analizan continuamente, pero en los que la agencia de los niños queda excluida. Los autores reclaman que los niños son ciudadanos con derechos y no meros sujetos de derecho derivado y apuntan a la necesidad de no contraponer sino de incluir las visiones tanto de adultos como de niños respecto a sus necesidades y experiencias. También se aborda la realidad de las infancias en el sentido de que no estamos ante un grupo homogéneo que los invisibiliza como hijos e hijas como tampoco debe hacerlo en una clase social única. Se reflexiona sobre qué papel tienen los niños en el cambio social y cómo influyen los diferentes procesos sociales en la infancia. Es decir, niño como sujeto receptor, pero también como agente de cambio.

Tal vez, una ausencia que se abre es una mayor indagación en cómo obran los cambios en las relaciones familiares y cómo intersecciona dicho cambio con las relaciones intergeneracionales. Surge la pregunta de si dichos cambios pueden analizarse desde el punto de vista de las cohortes (superando la visión del enfrentamiento intergeneracional vigente en la actualidad) y cómo unas y otras están adaptándose a cambios sociales de tal calado. Teniendo en cuenta la escasa investigación desde el prisma sociológico sobre las relaciones intergeneracionales (incluso más allá de las familiares) entre quienes pertenecen a la base de la pirámide y a quienes forman parte de la cúspide, hubiera sido interesante una reflexión comparativa más amplia y profunda, a fin de conocer si los cambios, riesgos y desafios que enfrentan las diferentes generaciones encuentran espacios comunes más allá de las transferencias de cuidados y económicas que se refieren para el caso de España.

En definitiva, es un libro necesario que resulta fácil de leer sin por ello perder las necesarias reflexiones teóricas sobre la sociología de la infancia. Los estudios de caso permiten contextualizar los fenómenos analizados en diferentes países, cimentados en un buen conocimiento de las realidades que se reflejan. 